\title{
Kinematic analysis of an en échelon-continuous vein complex
}

\author{
John P. Craddock and Ben A. van der Pluijm \\ Department of Geological Sciences, University of Michigan, 1006 C.C. Little Building, \\ Ann Arbor, MI 48109-1063, U.S.A.
}

(Received 11 December 1986; accepted in revised form 29 December 1987)

\begin{abstract}
An array of sigmoidal tension gashes from the Idaho-Wyoming thrust belt changes laterally into a continuous vein. Detailed mechanical twin analysis was used to determine the strain variation in the optically and chemically homogeneous blocky calcite filling. In the continuous portion of the vein complex, the shortening axes are parallel to the vein boundary. However, the orientation of the shortening axes in the tip areas of the sigmoidal gashes are at an angle of approximately $35^{\circ}$ to the vein boundary, and are parallel to the trend of the tips. Twinning patterns in the central portions of the gashes record two principal strain axes of shortening of nearly equal magnitude with the maximum perpendicular to the vein trend. Everywhere in the vein complex the orientation of the maximum extension axis is parallel to the twist axis of the gashes.

The petrofabric strain results show that the vein filling has largely recorded local strains. The pattern of variation in orientation of the principal strains in the vein complex is in close agreement with the theoreticallydetermined stress distribution in similar structures. Our results show that the sigmoidal gashes were formed at the leading edge of a propagating vein and that the sigmoidal shape reflects changes in the local strain field rather than a remote shear. The orientation of these local strains closely corresponds to the orientation of the local stresses.
\end{abstract}

\section{INTRODUCTION}

CRACKS in rocks are generally tensile (mode I) or shear (mode II) fractures (e.g. Roering 1968, Ramsay \& Graham 1970, Beach 1975, Logan et al. 1981, Rickard \& Rixon 1983). Filled cracks or veins provide information on the geologic history of the vein and host rock (e.g. Farmin 1941, Hancock 1972, Beach 1975, Ramsay 1980 , Pollard et al. 1982, Ramsay \& Huber 1983, Nicholson \& Pollard 1985). For example, the presence of fibrous vein filling has proven to be very useful in unraveling the progressive strain history of rocks (e.g. Durney \& Ramsay 1973, Ramsay \& Huber 1983, p. 235). However, in the absence of a characteristic vein filling texture, this interpretation is largely based on the shape of the crack. In this paper, we will present an analysis of a calcite vein complex that changes laterally from a continuous vein to an en échelon vein array that was filled with blocky calcite. Using detailed calcite twin analysis we will show that a considerable amount of information can be obtained about the kinematic history even from homogeneous vein filling.

Two interpretations have been given for sigmoidal gashes: (1) that they result from vein growth in a shear regime (Ramsay \& Graham 1970, type 1 of Beach 1975), or (2) that they are due to variation in the local stresses near the leading edge of a propagating vein (Hancock 1972, Pollard et al. 1982, type 2 of Beach 1975). In the former case the sigmoidal shape is a result of rotation of the initial (filled) crack while it continues to dilate (secondary origin), while in the latter case a remote shear regime is not necessarily present (primary origin).

We will discuss our results in view of other results from studies of complex vein systems and the significance of sigmoidal gashes in geologic environments. Throughout the text and in the figures we will use compression and tension for stress, and shortening and extension for strain. Tension and extension are given a positive sign, and clockwise rotation is taken as positive.

\section{GEOLOGICAL SETTING}

The sample analyzed was collected from the Lodgepole Limestone, the lower unit of the Mississippian Madison Group in the Absaroka thrust sheet at Haystack Peak near Bedford, Wyoming, in the IdahoWyoming Overthrust belt. Budai \& Wiltschko (1987) estimated that metamorphic temperatures in the Madison Group during thrust motion at this locality were about $75^{\circ} \mathrm{C}$. The fabric in outcrop consists of a well-developed pressure-solution cleavage and bands of tension gashes up to $10 \mathrm{~cm}$ wide, with individual gashes 5-9 cm long (Fig. 1a). Both the cleavage and veins can be correlated with movement of the sedimentary sequence over a ramp (see Oriel \& Platt 1980, Budai \& Wiltschko 1987). We will report on the results of our regional kinematic study in a separate contribution.

\section{MESOFABRIC}

The specimen we studied is shown in Figs. 1(b) \& (c); the corresponding schematic line drawing in Fig. 1(d) includes the reference system (axes $a, b$ and $c$ ) that is used throughout the text and figures. We only find the sigmoidal geometry on one surface (front in Fig. 1), yet the vein width is roughly equal on all four sides. The country rock is made up of partially dolomitized micritic limestone with pressure-solution seams, which do not seem to cross-cut the continuous portion of the vein (back), but locally post-date the en échelon array 
(front). The cleavage is therefore considered to be roughly contemporaneous with vein formation.

If we assume a shear zone interpretation for the sigmoidal vein array we can calculate the shear $\operatorname{strain}(\gamma)$ and the ellipticity $(R)$, and may inspect for dilation $(\Delta)$ (Ramsay \& Huber 1983, pp. 23 and 48). Assuming no area change, this would give a shear strain in the frontal face of the sample of 0.53 and a value for $R$ of 1.54 . The angle of $35^{\circ}$ between the orientation of the tips of gashes and the vein boundary measured in the front surface, however, indicates that dilation should also be considered (Ramsay \& Huber 1983, fig. 3.21). The twist angle (Pollard et al. 1982), $\omega$, is $30^{\circ}$. Alternatively, if the sigmoidal shape is primary, the above calculated values have no meaning and bear no relation to the actual strain in the sample. The results from our study suggest the latter is the case.

\section{MICROFABRIC AND CHEMISTRY}

In order to investigate the chemical and textural variation in the sample, we carried out optical and cathodoluminescence microscopy, microprobe analysis and measured the $c$-axis fabrics.
Cathodoluminescence did not reveal any variation in the nature of the vein filling, and neither fibrous vein growth, median surface nor crack-seal features were observed in transmitted light, although on one side of the sample a small piece of the host rock has been incorporated in the vein. Chemical variation was studied using the electron microprobe along traverses that were taken parallel and perpendicular to the vein boundary for both the front and back faces of the sample. No systematic variation in chemistry was observed and the average composition of vein calcite in both faces was indistinguishable.

Calcite $c$-axis, lower-hemisphere equal-area projections for the front and back faces of the sample are given in Fig. 2. They show a $c$-axis girdle around the $a c$-plane, but without a significant maximum. Evidence for widespread crystal plasticity other than twinning is absent. None of the grains appears to have undergone major recrystallization, and serrated grain boundaries can only be observed locally.

Fluid inclusions are present throughout the vein material but are too small $(<5 \mu \mathrm{m})$ to be useful in determining the pressure-temperature conditions at the time of vein filling; in any case they are probably secondary in origin.

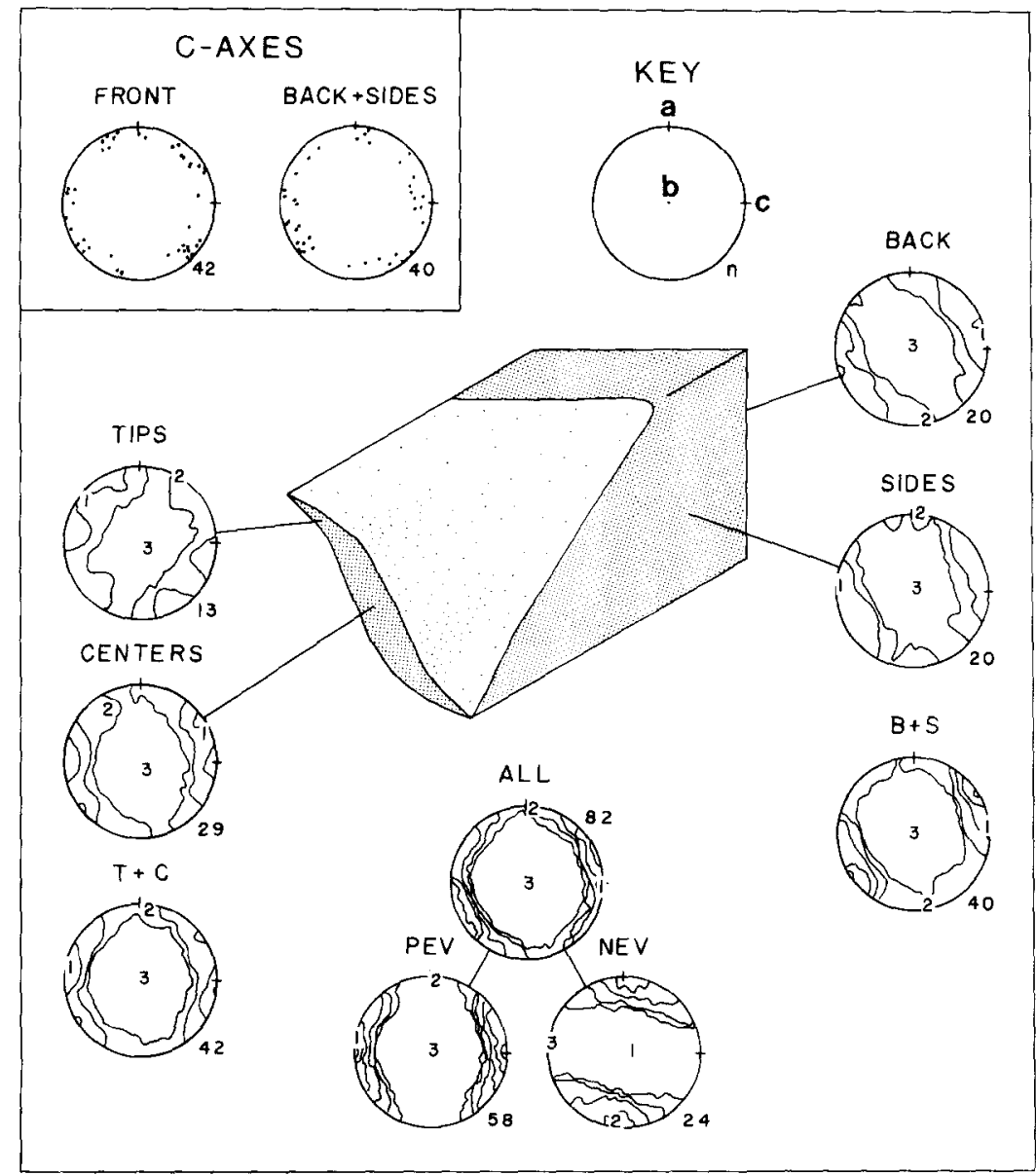

Fig. 2. $c$-axis fabrics from the front and back + sides of the sample, and the results from calcite mechanical twin analysis. Lower-hemisphere equal-area projections are used, and the orientations of the reference axes are indicated. Calcite twin data, represented by numbers 1,2 and 3 , give the orientation of the principal strain axes; $e_{1}$ and $e_{2}$ are negative and $e_{3}$ is positive, except in NEV where $e_{2}$ is also positive. In addition, contours of the compression axes are shown using increments of two standard deviations, starting with three. In all diagrams uncleaned data are presented. 
Kinematic analysis of a vein complex

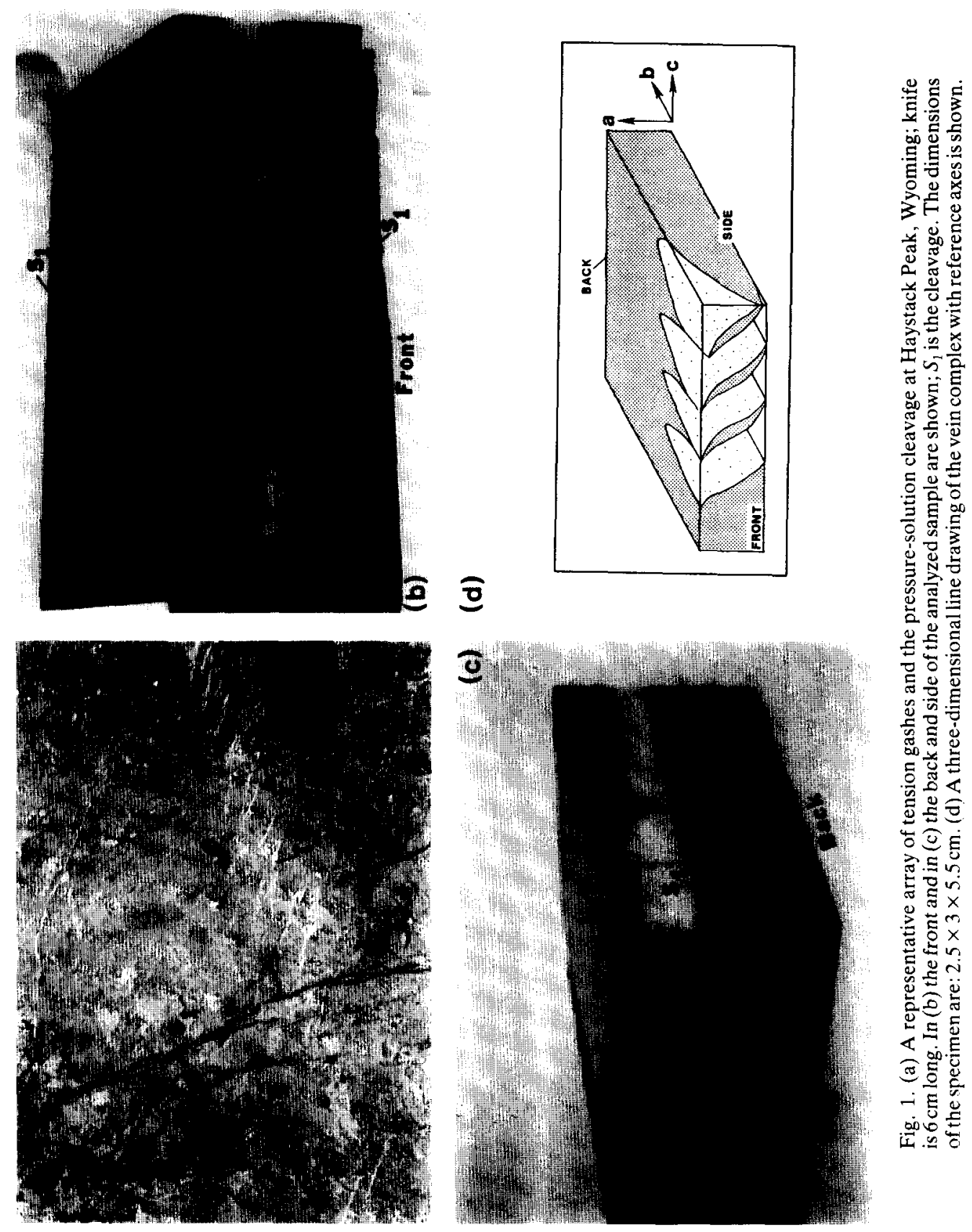





\section{CALCITE TWIN ANALYSIS: METHOD}

Mechanical twins in calcite were analyzed using the technique of Groshong (1972, 1974, Teufel 1980, Groshong et al. 1984b) to determine the orientation and magnitude of the principal strain axes associated with twinning. We distinguish negative expected values (NEVs) for grains that are not favorably oriented for twinning, and positive expected values (PEVs) for grains that give a positive sense of twinning.

Twins in the sample were measured on the four faces. The data were cleaned by eliminating the NEVs and/or eliminating $15-20 \%$ of the grains with the largest deviations (see Groshong 1974). Both methods only moderately reduced the error in strain magnitude while maintaining approximately the same orientation for the principal axes (within $5-10^{\circ}$ ). We attribute the limited effect of noise reduction to the relatively few twin sets per face we were able to measure, especially where a distinction between the tips and centers of the tension gashes was made. We have therefore decided to present the uncleaned data.

Calcite twin analysis gives values for the magnitude of strain and stress, but it is unable to detect volume changes and, in some cases, to recognize more than one deformational event (see below). Because of these properties and because of the large nominal errors in calculated strain magnitude (Table 1), we will emphasize the orientations of the principal strains in our discussion and attribute limited significance to the accompanying magnitudes. In experiments it has been demonstrated that the orientation of the principal strain axes is accurate to within 6-8 (Groshong et al. 1984b).

In addition to kinematic analysis, we applied the numerical dynamic analysis of Spang (1972) to the vein complex and calculated the differential stress magnitudes using the method of Jamison \& Spang (1976).

\section{CALCITE TWIN ANALYSIS: RESULTS}

Our results are presented in Tables 1 and 2 and Fig. 2 . Twinning was analyzed separately in the tips and centers
Table 2. Values of the differential stress magnitude calculated from the percentage of grains with three twin sets

\begin{tabular}{lccc}
\hline Location & $\begin{array}{c}\text { No. of } \\
\text { grains }\end{array}$ & $\begin{array}{c}\text { Threetwin } \\
\text { sets } \\
(\%)\end{array}$ & $\begin{array}{c}\text { Differential } \\
\text { stress } \\
\text { (MPa) }\end{array}$ \\
\hline Centers + tips & 100 & 3 & 100 \\
Back + sides & 200 & 6.5 & 157 \\
All & 300 & 5.5 & 130 \\
\hline
\end{tabular}

Critical resolved shear stress for calcite twinning is $10 \mathrm{MPa}$.

of the tension gashes (front), the sides and the back. The data were rotated and merged in various combinations, and the results are presented below.

\section{Tips}

We were only able to carry out twin analysis on 13 grains, of which three had negative expected values (NEVs). This is too small a number to split and analyze separately. The shortening axis lies at an angle of $-55^{\circ}$ from $a$ with a magnitude of $14.7 \%$; the extension direction is approximately perpendicular to the front face, that is parallel to the twist axis of the tension gashes (axis b). Note that the nominal error (Groshong et al. 1984b) is very high (15.9), which is attributed to the relatively small number of grains.

\section{Centers}

Twenty-nine grains from the central portions of the tension gashes gave a maximum shortening direction that lies in the $a c$-plane, at an angle of $+65^{\circ}$ from $a$. However, only little difference in magnitude $(2 \%)$ was found between $e_{1}$ and $e_{2}$. The extension direction is parallel to that obtained from the tips but considerably smaller in magnitude. Thirty-one per cent of the grains had NEVs.

\section{Tips + centers}

When data from the two above sets are combined the strain axes are approximately parallel to our reference axes, with $e_{1}$ parallel to $c$ and $e_{2}$ parallel to $a$.

Table 1. Results from calcite mechanical twin analysis for the different areas of the vein complex shown in Fig. 1. The orientations of the principal strains are shown in Fig. 2

\begin{tabular}{|c|c|c|c|c|c|c|}
\hline Location & $\begin{array}{l}\text { No. of } \\
\text { grains }\end{array}$ & $e_{1}$ & $\begin{array}{c}\text { pal strai } \\
(\%) \\
e_{2}\end{array}$ & $e_{3}$ & $\begin{array}{l}\text { Nominal } \\
\text { error }\end{array}$ & $\begin{array}{c}\text { NEVSA } \\
(\%)\end{array}$ \\
\hline Centers & 29 & -7.2 & -5.1 & 12.3 & 8.0 & 31 \\
\hline Tips & 13 & -14.7 & -6.9 & 21.6 & 15.9 & 23 \\
\hline Center + tips & 42 & -12.2 & -7.9 & 20.1 & 6.7 & 29 \\
\hline Back & 20 & -19.1 & -16.0 & 35.0 & 10.4 & 25 \\
\hline Sides & 20 & -17.3 & -14.0 & 31.2 & 4.2 & 30 \\
\hline Back + sides & 40 & -22.3 & -17.5 & 39.8 & 6.3 & 25 \\
\hline All & 82 & -12.7 & -9.0 & 21.6 & 3.3 & 29 \\
\hline PEV & 58 & -17.9 & -9.8 & 27.7 & 2.6 & 7 \\
\hline NEV市 & 24 & -29.1 & 11.7 & 17.4 & 4.0 & 4 \\
\hline
\end{tabular}

${ }^{*}$ Deviatoric strain: $e_{1}+e_{2}+e_{3}=0$; extension is positive.

+ Nominal error $=\mathrm{SE}(X)+\mathrm{SE}(Y) / 2($ Groshong et al. 1984b); SE is standard error.

$\$ P E V$ and NEV are positive and negative expected value, respectively. 
The results from twin analysis of the sides are similar to those for tips + centers above. However, the strain magnitudes are considerably higher. The maximum shortening strain is $17.3 \%$, and $30 \%$ of the grains had NEVs.

\section{Back}

The back face allowed for the analysis of 20 grains, of which $25 \%$ gave NEVs. The strain axes are again parallel to our reference system axes, with a maximum shortening strain of $19.1 \%$. The extension axis $\left(e_{3}\right)$ is parallel to $b$, as for the other faces of the vein complex.

Sides + back

Because the side and back faces both represent the continuous portion of the vein, contrasting with the sigmoidal en échelon shape on the front face, data for the two were combined. Predictably, the pattern is similar to those of the two faces separately.

\section{All, PEV, NEV}

All data were combined into one set of 82 grains and analyzed (All in Table 1 and Fig. 2). Twenty-nine per cent of the grains had NEVs, and separate NEV- and PEV-splits were run. The PEV-split produced a pattern indistinguishable in orientation from that for back + side or tips + centers. However, a contrasting pattern was obtained from the NEV-split. The compression axis contour maximum is parallel to $a$ while the shortening direction (magnitude: $29.1 \%$ ) is parallel to $b$. Thus the NEV-split may suggest a second, unrelated deformational event that is orthogonal to the first. Teufel (1980) showed that two deformational events can be distinguished when more than $40 \%$ NEVs are present and when the errors for split runs are smaller than that for the complete set. Our results give approximately $30 \% \mathrm{NEVs}$ for all areas in the vein and no real reduction in standard error between the All and the PEV and NEV runs (Table 1). Thus these data cannot be used to confirm the presence of more than one deformational event.

\section{Differential stress}

Twinning in calcite can occur on three twin planes, and the proportion of deformed grains with one, two or three twin sets within a sample can be used to infer the differential stress at the time of twinning (Jamison \& Spang 1976). All of the calcite grains in the vein filling had at least two twin sets, so the proportion of grains with three sets were counted, and these data are presented in Table 2. A differential stress in the range of 100-160 MPa was calculated for the time of twinning, using a critical resolved shear stress (CRSS) of $10 \mathrm{MPa}$ (Wenk 1985).
We found no variation in chemistry or texture across the vein complex, which indicates that the metamorphic and kinematic conditions did not change appreciably during vein filling. This in turn would suggest that vein filling occurred during a single event, possibly reflecting a geologically short time span.

\section{Variation in strain and stress}

In order to interpret the results from twin analysis it is critical to distinguish between the stress field that produced the crack, that is the remote stresses, and the stress field associated with the evolution of these discontinuities, that is, the local stresses. Thus, strains in the vein material as a result of propagation will be different from those related to crack formation.

Earlier studies (e.g. Pollard et al. 1982 and references therein) have demonstrated that vein propagation takes place from the continuous portion ('parent') to the discontinuous, en échelon portion of the vein, parallel to the twist axis. Furthermore, it is generally accepted that cracks propagate in a plane normal to the remote tensile stress. All analyzed parts of our vein complex show the extension axis to be parallel to the vein boundary and the twist axis of the en échelon array. Since the remote extension axis associated with the formation of the vein would be at a high angle to the vein boundary we interpret the calculated $e_{3}$ orientation to reflect the local field that is associated with crack propagation.

In the continuous portion of the vein complex we find that the shortening axis consistently lies in the vein boundary surface, parallel to $c$ (Fig. 2). Thus, $e_{1}$ and $e_{2}$ largely seem to reflect the remote stresses. Toward the leading edge of the vein (the en échelon array) this pattern changes. The maximum shortening axis in the tip area lies at an angle of $-55^{\circ}$ from $a$. This orientation is parallel to the trend of the tips (Fig. 2). In contrast, in the center of the gashes the compression and shortening axes are perpendicular to the vein trend (Fig. 2) with very little difference in magnitude between $e_{1}$ and $e_{2}$ (Table 1). The rotation axis of the stress and strain fields from tips to centers, as well as from continuous to discontinuous portions of the vein, is parallel to the twist axis (here $b$ ) of the vein complex.

Following Pollard et al. (1982) and Nicholson \& Pollard (1985) we interpret the change in orientation of the strain from the continuous to the discontinuous portions of the vein to be a result of the breakdown of the parent crack into an en échelon array in the direction of vein propagation. The orientation of the strain in the tips and centers of the en échelon array tracks the geometry of the sigmoidal gashes, and the small differential strain magnitude $\left(e_{1}-e_{2}\right)$ in the centers of the gashes reflects the greater role of interaction between neighboring cracks.

Finally it should be noted that the calcite twinning strains observed in the vein complex are unrelated to the strain distribution in the country rock. Strain patterns 
in the Idaho-Wyoming thrust belt dominantly show bedding-parallel shortening fabrics (Craddock et al. in press), as is well documented for other thrust belts (e.g. the Alps, Groshong et al. 1984a; the southern Appalachians, Wiltschko et al. 1985).

In conclusion, the deformed vein filling in different areas of the vein complex recorded the remote and local stresses in different proportions. The sigmoidal, en échelon array was formed at the leading edge of the propagating vein and largely reflects the local field and not the remote shear.

\section{Magnitudes of strain and differential stress}

Calculated shortening strain magnitudes range from 5.1 to $22.3 \%$ (Table 1 ), with a mean differential strain $\left(e_{1}-e_{2}\right)$ of $4.2 \%$. An overall decrease in strain magnitude is observed from the continuous to discontinuous portion of the vein complex, that is, in the direction of propagation. In the absence of better constrained values (see nominal errors) and information on volume changes we only conclude that there were two principal shortening directions of only slightly different magnitude.

Differential stress magnitudes calculated from twinned calcite are in the range of $100-157 \mathrm{MPa}$ with an average of $130 \mathrm{MPa}$, which equates to a maximum shear stress of approximately $65 \mathrm{MPa}$. Jamison \& Spang (1976) noted that the value for the differential stress using their method probably represents an upper value. In spite of the crudeness of this method, these values are consistent with results obtained by Jamison \& Spang (1976) and House \& Gray (1982) from low-grade rocks in other thrust terranes. Following Etheridge (1983), the tensile strength of the rock would be greater than $30 \mathrm{MPa}$ $\left(\left(\sigma_{1}-\sigma_{3}\right) \leqslant 4 T\right)$, which is at the high end of the scale of measured tensile strengths of rocks (e.g. Suppe 1985, p. 155). This high value is attributed to the fine-grained dolomitic nature of the Madison Group in which the vein structure was formed.

\section{Relationship between twin analysis and c-axis fabric}

Since the early 1950 s it has been known that $c$-axes in deformed calcite tend to develop girdles perpendicular to the tension axis when calcite twinning is the dominant deformation mechanism (e.g. Turner \& Weiss 1963, Wenk 1985). Both $c$-axis fabrics in Fig. 2 show an orthorhombic symmetry, but the relatively small number of axes that could be measured do not allow great significance to be attached to the maxima in these girdles. Note, however, that for the continuous vein the $c$-axis contours appear to be concentrated around the compression axes that were calculated from dynamic twin analysis (Fig. 2). Our $c$-axis fabrics indicate that the sample underwent axially-symmetric extension parallel to $b$, which is in agreement with the strains that were measured from calcite twinning (Table 1).

Acknowledgements-We thank Patti Craddock, Anne Campbell, Dave Wiltschko and Joyce Budai for field assistance and discussions, Rick Groshong and Dave Wiltschko for allowing use of calcite strain programs, Ina Hanel for fluid inclusion work, and Carl Henderson for assistance with microprobe analysis that was carricd out at the R. B. Mitchell Electron Microbeam Analysis Laboratory of the University of Michigan. Comments by Sue Beck and Andy Schedl, and reviews by Rick Groshong, Peter Hudleston and an anonymous reviewer significantly improved the paper. Research was supported by a University of Michigan Rackham faculty grant.

\section{REFERENCES}

Beach, A. 1975. The geometry of en-échelon vein arrays. Tectonophysics 28, 245-263.

Budai, J. M. \& Wiltschko, D. V. 1987. Structural controls on syntectonic diagenesis within the Haystack Peak region of the Absaroka thrust sheet, Idaho-Wyoming-Utah thrust belt. Wyoming Geol. Ass. Guidebook, 55-68.

Craddock, J. P., Kopania, A. \& Wiltschko, D. V. In press. Interaction between the northern Idaho-Wyoming thrust belt and bounding basement blocks. Spec. Pap. geol. Soc. Am.

Durney, D. W. \& Ramsay, J. G. 1973. Incremental strains measured by syntectonic crystal growths. In: Gravity and Tectonics (edited by de Jong, K. A. \& Scholten, R.). John Wiley, New York, 67-96.

Etheridge, M. A. 1983. Differential stress magnitudes during regional deformation and metamorphism: upper bound imposed by tensile fracturing. Geology 11, 231-234

Farmin, R. 1941. Host-rock inflation by veins and dikes at Grass Valley, California. Econ. Geol. 36, 143-174.

Groshong, R. H., Jr. 1972. Strain calculated from twinning in calcite. Bull. geol. Soc. Am. 83, 2025-2048.

Groshong, R. H., Jr. 1974. Experimental test of the least squares strain gage calculation using twinned calcite. Bull. geol. Soc. Am. 85, 1855-1864.

Groshong, R. H., Jr, Pfiffner, O. A. \& Pringle, L.. R. 1984a. Strain partitioning in the Helvetic thrust belt of eastern Switzerland from leading edge to the internal zone. J. Struct. Geol. 6, 19-32.

Groshong, R. H., Jr, Teufel, L. W. \& Gasteiger, C. 1984b. Precision and accuracy of the calcite strain gage technique. Bull. geol. Soc. Am. 95, 357-363.

Hancock, P. L. 1972. The analysis of en-échelon veins. Geol. Mag. 109, 269-276

House, W. M. \& Gray, D. G. 1982. Cataclasites along the Saliville thrust, U.S.A. and their implications for thrust-sheet emplacement. J. Struct. Geol. 4, 257-269.

Jamison, W. R. \& Spang, J. H. 1976. Use of calcite twin lamellae to infer differential stress. Bull. geol. Soc. Am. 87. 868-872.

Logan, J. M. , Higgs, N. G. \& Friedman, M. 1981. Laboratory studies on natural gouge from the U.S. Geological Survey Dry Lake Valley No. 1 well, San Andreas fault zone. Am. Geophys. Union Monograph 24, 121-134.

Nicholson, R. \& Pollard, D. D. 1985. Dilation and linkitge of echelon cracks. J. Struct. Geol. 7, 583-590.

Oriel, S. S. \& Platt, L. B. 1980. Geologic map of the Preston $1 \times 2$ degree quadrangle, southeastern Idaho and western Wyoming. U.S. Geol. Surv. map I-1127.

Pollard, D. D., Segall, P. \& Delaney, P. T. 1982. Formation and interpretation of dilatant echelon cracks. Bull. geol. Soc. Am. 93. 1291-1303

Ramsay, J. G. 1980. Shear zone geometry: a review. J. Struct. Geol. 2. 83-99.

Ramsay, J. G. \& Graham, R. H. 1970. Strain variation in shear belts. Can.J. Earth Sci. 7, 786-813.

Ramsay, J. G. \& Huber, M. I. 1983. The Techniques of Modern Structural Geology, Volume 1: Strain Analysi:. Academic Press, London.

Rickard, M. J. \& Rixon, L. K. 1983. Stress configurations in conjugate quartz-vein arrays. J. Struct. Geol. 5, 573-578.

Roering, C. 1968. The geometrical significance of natural en-échelon crack-arrays. Tectonophysics 5, 107-123

Spang, J. H. 1972. Numerical method for dynamic analysis of calcite twin lamellae. Bull. geol. Soc. Am. 83, 467-472.

Suppe, J. 1985. Principles of Structural Geology. Prentice-Hall, Englewood Cliffs, New Jersey.

Teufel, L. W. 1980. Strain analysis of experimentally superposed deformation using calcite twin lamellae. Tectonophysics $\mathbf{6 5}, 291$. 309.

Turner, F. J. \& Weiss, L. E. 1963. Structural Analysis of Metamorphic Tectonites. McGraw-Hill, New York. 
Wenk, H.-R. 1985. Carbonates. In: Preferred Orientation in Deformed Metals and Rocks: An Introduction to Modern Texture Analysis (edited by Wenk, H.-R.). Academic Press, Orlando, 361-384. Wiltschko, D. V., Medwedeff, D. A. \& Millson, H. E. 1985. Distri- bution and mechanisms of strain within rocks on the northwest ramp of Pine Mountain block, southern Appalachian foreland: a field test of theory. Bull. geol. Soc. Am. 96, 426-435. 